\title{
Modelling of the grain materials 'shredding process for the purposes of the beater shredders' designing
}

\author{
Andrzej Bochat ${ }^{1}$, and Marcin Zastempowski ${ }^{1 *}$ \\ ${ }^{1}$ UTP University of Science and Technology in Bydgoszcz, Faculty of Mechanical Engineering, \\ Al. prof. S. Kaliskiego 7, 85-796 Bydgoszcz, Poland
}

\begin{abstract}
Within the frames of the study's performance, the modeling attempt of the gran materials' shredding with the beater shredder was taken up. Modelling was conducted for two constructions of working shredder's assemblies, that is for a classical and a new one, developed by the study's authors. The classical construction is characterised by the fact, that it has beaters assembled to the rotor of a cuboid shape. However, the new construction, has beaters in the shape of a circular section. It results from the conducted shredding process' analysis, that the shape of the beaters has a crucial impact on the shredding output's increase at simultaneous decrease of the process' energy consumption. The developed kinematics and energy consumption models of the shredding process may be used at the phase of the beater shredders' designing for grain materials.
\end{abstract}

\section{Introduction}

Shredding is the process of the material's splitting into smaller particles with the use of machines' working parts, overcoming the cohesion forces of the material's particles. Materials' shredding is the effect of influencing such processes as: splitting, crushing, grinding or breaking by the materials particles' hitting. While selecting of the shredding method, there have to be considered the shredded material's mechanical properties, selecting such a manner of the working element's operating as to obtain the required shredding degree at possibly the lowest destructive stresses of the shredded material. In the professional literature, the process of shredding is considered most often in three fundamental perspectives, that is productivity, energy consumption and the shredding degree. The subject matter of the gran materials' shredding is being widely entered into in the available literature, both with the reference to the process' effectiveness as well as new constructions of the shredders' working assemblies [1-4].

In the economy (mining industry, chemical industry, food processing industry), the following types of shredders are commonly used:

- beater shredders,

- crushing mills,

- radial plate grinding mills,

- roller mills.

Quick designing of that type of machines requires, among the others existence of appropriate mathematical models describing the shredding processes conducted by the.

Within the frames of the study's performance, developing of the models for the classical and innovative beater shredder's construction was undertaken. The innovative construction of the shredder is original and patented.

\footnotetext{
* Corresponding author: zastemp@utp.edu.pl
} 


\section{The essence of the classical and innovative construction of the beater shredder}

The fundamental elements of a typical beater shredder are the rotor with self-aligning or stiffy mounted beaters, a shredder's sieve or sieves, a shredding plate or plates and a supporting structure with a power transmission system. In beater shredders, the material shifts from the charging hopper to the working area, in which there is a rotor with beaters. The supplied material reaches a considerable speed $(40-110 \mathrm{~m} / \mathrm{s})$ under the influence of the beaters' strokes and moves on the circular path hitting a sieve (or sieves) and one another. As a result of the percussive forces' effect, the shredded material remains in the shredding chamber as long, till it gets the particles' dimensions smaller than the holes in sieves. The shredded material, having reached appropriate geometrical features, comes through outside the shredder's chamber through the holes in the sieves.

A flaw and an inconvenience of the known, classical design solutions of the beater shredders is their low throughput as compared to the energy consumption [5-9]. It is determined most of all $\mathrm{b}$ a rotor's construction, where the beaters are of the shape of rectangular plates. As an effect of that, under the impact of the beaters' strokes, the material's particles start to move along the paths similar to a circle. They form a thin layer oscillating on the shredding chamber's internal perimeter, what results in the fact that in spite of sometimes sufficient shredding degree, the material is circling still for a long time before it passes through the holes in the sieves. In figure 1 the classical rotor of a beater shredder in the isometric view is presented.

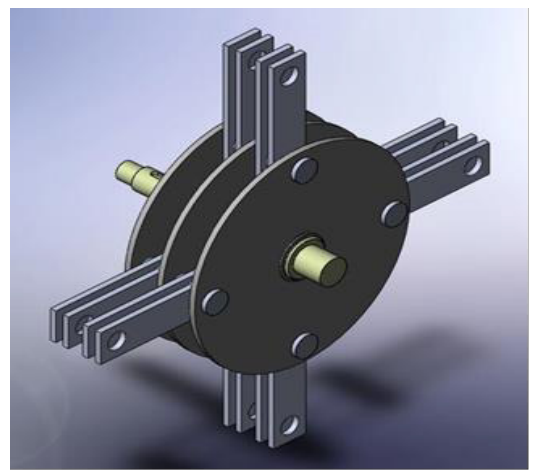

Fig. 1. The isometric view of a classical beater shredder's rotor with rectangular beaters $\left(\alpha=0^{\circ}\right)$, designed in the Solid Works programme.

The essence of the new construction consists in the fact, that the shredder's working assembly consists of a disk rotor mounted on a shaft on which the self-aligning beaters are assembled. The beaters are of plates' shape in the form of a circular section of the angle of flare of at least 350, while the beater's fastening opening is on the symmetry axis of the circular section close to its arc bed. Such a construction of a beater shredder's rotor resuls in the fact, that the shredded material's particles, hit by the beaters, do not move along the circular path and do not form a rotaring ring, but they move approximately radially with reference to the sieves and they immediately hit them. It results in quicker material's passing through the holes in the sieves. In figure 2 there is presented a new construction of a beater shredder's rotor in isometric view. The presented new solution of a beater shredder's rotor is the subject matter of the patent of the Republic of Poland no 173497 (Bochat A.). 


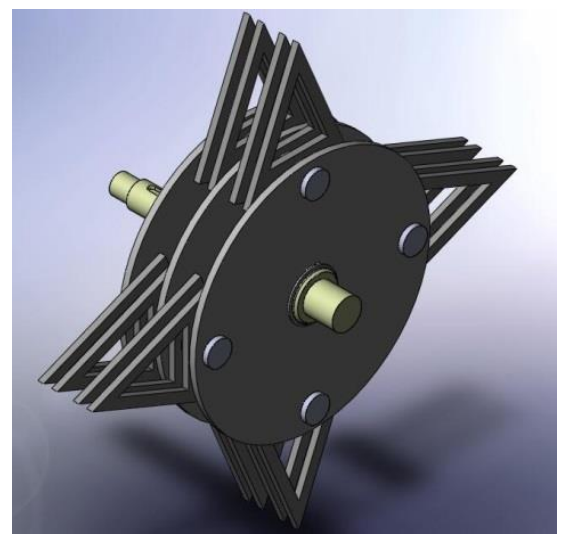

Fig. 2. The isometric view of the innovative construction of a beater shredder's rotor with beaters in the shape of a circular section $\left(\alpha=45^{\circ}\right)$, designed in the Solid Works programme.

Shredding of the grain material is most of all conducted with mechanical methods, and on the process' effectiveness [10] there decide the physiomechanical material's properties [11] as well as the constructional and exploitation shredders' features. The following may be counted among the others as the constructional and exploitation features: shape, dimensions and construction of the shredder's working assembly, kinematic and dynamic process' parameters [12], level of wear and tear as well as resistance to mechanical destruction of working elements. Resistance to mechanical destructions is determined, among the others, by conducting studies on the strength of materials from which the component elements of the working assembly have been made of [13-16], while the wear and tear may be forecasted based on modelling of the machines elements' conditions [17].

\section{Modelling of the kinematics of the grain materials' shredding process}

In the beater shredder, tha grain materia lis shredded by a beater's hitting the matrial and the material's hitting the sieves. The shredded material passes through the shredding chambers outside through the sieve. The grain material which is in the working chamber, rotates till it reaches the required shredding degree. The degree of the material's shredding depends on the circumferential speed of the beaters, the shape of the beaters, the angle of contact and the size of the holes in the sieves. The efficiency W of the shredded may be described with the dependence:

where:

$$
W=\frac{m}{t}
$$

$m \quad$ - mass of the shredded material,

$t \quad$ - $\quad$ time of the material's staying in the shredder's working chamber.

The time of the grain material's staying in the working chamber, depends on the multiplicity of circulation $k$ and the average speed of the circulating grain mass. The average value has been assumed to be the resultant speed of the shredded material's particle in the beater's middle length:

where:

$$
k=\frac{v_{w} t}{2 \pi r}=\frac{m v_{w}}{W 2 \pi r}
$$

$k \quad$ - multiplicity of the material's circulation in the working chamber,

$v_{w} \quad$ - resultant speed of the circulating grain, falling on the beater's active middle length,

$r \quad$ - distance of the shredder's rotor axis of rotation measured to the middle of the beater's active

length 
The speed of the moving grains in the working chamber, depends on the rotor's rotational speed and the applied constructional solution of the beaters. The figure 3 presents the distribution of the grain particle's speed, which is in the beater shredder's working chamber considering the beaters' shape. In case of shredding the grains with the use of the beaters of the shape of the rectangular prism (fig. 3a), then the normal speed vector which equals to the peripheral tangential speed of the shredded particle equals to zero, and the normal speed vector is equal to the peripheral speed, falling on the half of the active beater's length.

So:

where:

$$
\begin{aligned}
& v_{n}=\omega r \\
& v_{n}=v_{r},
\end{aligned}
$$

$v_{n} \quad$ - normal speed of the shredded material's particle,

$v_{r} \quad$ - peripheral beater's speed measured to the half of the active beater's length,

$\omega \quad$ - $\quad$ angular speed of the beater's rotor.

Application of a beater in the shape of the perpendicular prism results in the fact, that the shredded material oscillates in the shredding chamber, forming an oscillating ring. Inconvenience of such a solution is the decrease of the shredding process' efficiency, and the increase of the dusty fraction's content [5].
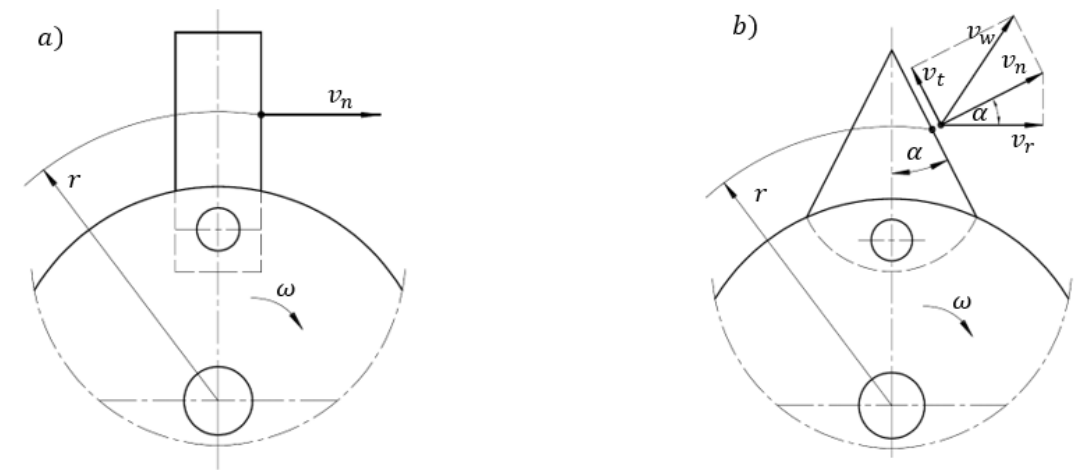

Fig. 3. Diagram of the grain speed's distribution at the moment of hitting the beater: a) the beater in the shape of a rectangular prism, b) the beater in the shape of a circular section.

In case of the gran material's shredding with a working assembly with beaters in the shape of a circular section (fig. 3b), the normal speed of the shredded particle equals to the relation of the peripheral beater's speed to the beater's angle cosine. The direction of the resultant speed's value of the shredded particle depends on the rotor's speed and the angle between the front beater's surface and its symmetry axis:

$$
\begin{gathered}
v_{r}=\omega r \\
v_{n}=\frac{v_{r}}{\cos \alpha}=\frac{\omega r}{\cos \alpha} \\
v_{w}=\frac{v_{n}}{\cos \alpha}=\frac{\omega r}{\cos ^{2} \alpha},
\end{gathered}
$$

where:

$\alpha \quad$ - angle of the beater.

Applying in the shredder's rotor of the beater in the shape of a circular section results in the fact, that the shredded particles do not form an oscillating ring, but they collapse at a 
bigger angle on the sieve's surface and are disposed of outside the working chamber (fig. 4a and $4 b)$.

a)

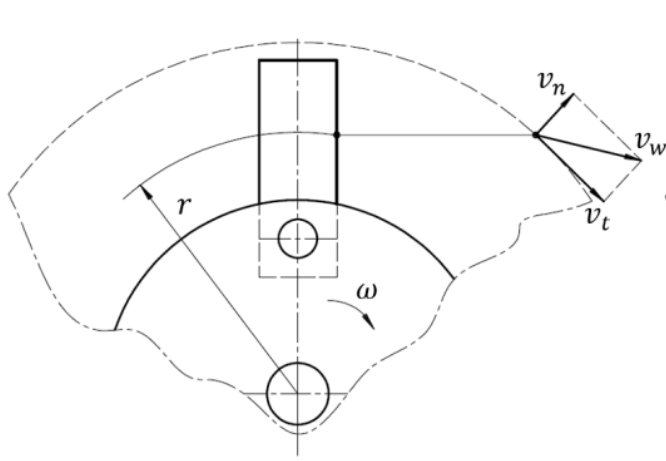

b)

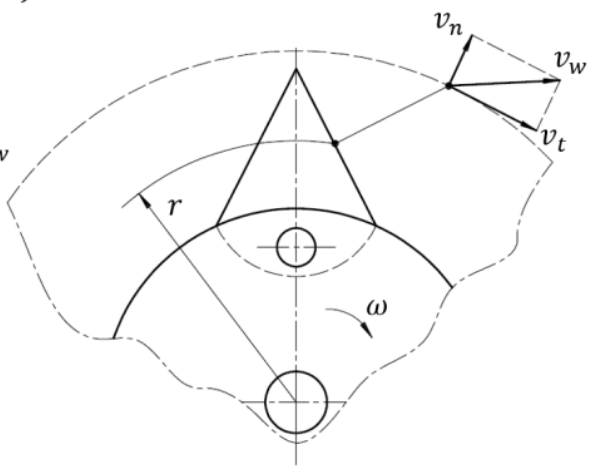

Fig. 4. Diagram of the gran speed's distribution while hitting the sieve: a) the beater in the shape of a rectangular prism, b) the beater in the shape of a circular section.

\section{Modelling of the shredding's energy consumption in the beater shredder}

Energy consumption of the beater shredders depends on their features and design parameters as well as on the shredded material's properties. The summary energy $E_{c}$ necessary for the shredding process' conducting, is the sum of the shredding energy and the energy of the running light:

where:

$$
E_{c}=E_{r}+E_{l}
$$

$E_{r} \quad$ - shredding power rozdrabniania,

$E_{l} \quad$ - power of the shredder's running light.

Te shredded material's power may be determined based on the dependence:

whereas

$$
E_{r}=E_{c}-E_{l} \text {, }
$$

where:

$$
E_{c}=E_{j} m
$$

$E_{j} \quad$ - unit power of shredding,

$m$ - mass of the shredded grain material.

The unit energy necessary for conducting of the material's splitting, is the function of power intake by the bear shredder's working assembly with respect to the volume of the shredded material. Considering of this process with respect to the mass unit, the formula fot the unit energy is received:

$$
E_{j}=\frac{N}{W}
$$

where:

$N \quad$ - intake of power by the shredder's working assembly,

$W$ - efficiency of the shredder.

The shredding process in the beater shredder is the most intensive on the rotor's circumference, so in order to calculate the power demand it may be assumed, that the material's particle having hit the beater, changes its speed for $\Delta \omega$, where the change of this speed is proportional to the resultant speed of the shredded material's particle on the beater's mid length. The power needed for the material's shredding is the product of the shredded particle's resultant speed and of the shredding power. However, the power of the running 
lights' resistance is the function of the turning moment and the angular speed in respect of time needed for its shredding.

So:

$$
\begin{aligned}
& N_{c}=F v_{w}, \\
& N_{o}=\frac{J \omega^{2}}{2 t},
\end{aligned}
$$

where:

$N_{c} \quad$ - power necessary for the material's shredding,

$F \quad$ - resisting force of the the particles' shredding on the rotor's circumference,

$N_{o} \quad$ - the shredder's power of running light,

$J \quad$ - moment of inertia of the shredder's working assembly.

Here it should be pointed out, thay one of the inconveniences of the shredding process is the fact, that the shredded material, in spite of reaching the demanded shredding degree, oscillates in the shredder's working space. Due to that, there may be singled out the useful and unessential hits, which result in linger material's staying in the working chamber. The experimental data point out, that shredding of the grain materials takes place most often at the hitting speed of $40 \mathrm{~m} / \mathrm{s}$ and 30-40 hits. Assuming, that in time $t$ there shall be shreaded material of the mass $m$, the number of total hits $n$ resulting in the material's shredding, is equal to:

where:

$$
n=z \frac{\omega}{2 \pi} t
$$

$z \quad$ - number of the beaters.

Mass of the material circulating in the shredder's chamber, has been determined based on the design features of the shredding chamber :

where:

$$
m=2 \pi r L h_{m} \rho c_{m}
$$

$L \quad$ - width of the working assembly (rotor),

$h_{m}$ - thickness of the circulating material's layer,

$\rho \quad$ - the shredded material's density,

$c_{m}$ - material's concentration in the shredding chamber.

So, following the transformations, the shredding energy's equation assumes the form:

$$
E_{r}=E_{j} m-\frac{J \omega^{2}}{2}=z \frac{\omega}{2 \pi} t m v_{w}^{2} B-\frac{J \omega^{2}}{2}=z r L h_{m} \rho c_{m} t m v_{w}^{2} B-\frac{J \omega^{2}}{2},
$$

where:

$B$ - proportionality coefficient resulting from the fact, that the change of the speed $\Delta \omega$ is proportional to the beaters' peripheral speed.

\section{Summary}

From the conducted analysis of the shredding process it results, thay the shape of the beaters has a fundamental impact on the energy consumption of the shredding process conducted with the beater shredder. The resultant speed and the direction of the shredded material's flight, determine the time of its staying in the shredder's chamber and the process' energy consumption. Losses of energy resulting from the grains' friction without the effect of their shredding as well as the losses of the kinematic and potential energy connected with the grains' deformation, are a big inconvenience of the shredding process. However, most of these losses are hard to be assessed to be described mathematically. Due to the above, the developed model should be experimentally verified at the time of gran materials' shredding of different physio-mechanical properties. The developed models of thee shredding process kinematics and energy-consumption, following their positive verification, may be used at the stahe of the the beater shredders' designing. 


\section{References}

1. A. Tomporowski, J. Flizikowski, A. Al-Zubiedy, Przemysl Chemiczny, 97, 2 (2018)

2. A. Tomporowski, J. Flizikowski, W. Kruszelnicka, Przemysl Chemiczny, 96, 8 (2017)

3. M. Zastempowski, A. Bochat, 6th International Conference on Trends in Agricultural Engineering (TAE),: Czech Univ Life Sci, Prague, 726-735 (2016)

4. M. Zastempowski, S. Borowski, J. Kaszkowiak, 5th International Conference on Trends in Agricultural Engineering, Czech Univ Life Sci, Prague, 673-676 (2013)

5. A. Bochat, L. Wesołowski, M. Zastempowski, Transactions of ASABE, 58,3, (2015)

6. M. Chwiej. Roczniki Nauk Rolniczych, 76, 9-19 (1986)

7. P.C. Kaptur, K. Schoenert, D. Furstenau, International Journal of Mineral Processing, 29, 221-233 (1990)

8. S. Obidziński, R. Hejft, Zeszyty Naukowe Politechniki Opolskiej, 60, 185-193 (2000)

9. M. Opielak, H. Komsta, Zeszyty Naukowe Politechniki Opolskiej, 60, 209-217 (2000)

10. A. Tomporowski, ski, Eksploatacja i Niezawodnosc-Maintenance and Reliability, 2, 150 (2012)

11. W. Keska, L. Gierz, 69th International Conference on Agricultural Engineering LAND TECHNIK AgEng. Hannover, GERMANY, 459-464, (2011)

12. A. Bochat, M. Zastempowski, Transactions of the ASABE, 56, 4 (2013)

13. B. Ligaj, G. Szala, Polish Maritime Research, 17, 1 (2010)

14. T. Piątkowski, J. Sempruch, T. Tomaszewski,Transactions of the Canadian Society for Mechanical Engineering, 38, 1 (2014)

15. T. Tomaszewski, P. Strzelecki, J. Sempruch, 22nd International Conference on Engineering Mechanics, Svratka, Czech Republic (2016)

16. G. Szala, B. Ligaj, International Journal of Fatigue, 91, 39-49 (2016)

17. L. Knopik, K. Migawa, Eksploatacja i Niezawodnosc - Maintenance and Reliability, 20, $1(2018)$ 